Article

\title{
Dynamics of Paddy Field Patterns in Response to Urbanization: A Case Study of the Hang-Jia-Hu Plain
}

\section{Jie Song ${ }^{1}$, Dongyan Cai ${ }^{1}$, Jinsong Deng ${ }^{1,2, *}$, Ke Wang ${ }^{1, *}$ and Zhangquan Shen ${ }^{1}$}

1 Institution of Remote Sensing and Information System Application, Zhejiang University, Hangzhou 310058, China; E-Mails: 11214051@zju.edu.cn (J.S.); 21314119@zju.edu.cn (D.C.); zhqshen@zju.edu.cn (Z.S.)

2 School of Civil Engineering and Environmental Sciences and School of Meteorology, University of Oklahoma, Norman, OK 73019, USA

* Authors to whom correspondence should be addressed; E-Mails: jsong_deng@zju.edu.cn (J.D.); kwang@zju.edu.cn (K.W.); Tel.: +86-571-8898-2272 (K.W.); Fax: +86-571-8898-2297 (K.W.).

Academic Editor: Marc A. Rosen

Received: 1 September 2015 / Accepted: 8 October 2015 / Published: 14 October 2015

\begin{abstract}
Urban land has increasingly expanded and encroached upon a significant number of paddy fields in Hang-Jia-Hu Plain, due to the rapid socio-economic development and agro-pedoclimatic conditions favorable to rice cultivation and human settlement. Although many studies have analyzed the characteristics of urban land expansion, relatively less attention has been paid to exploring the various urban expansion patterns and the impact of different urban expansion patterns on paddy field at a regional scale. This paper characterized the changing patterns of paddy fields in response to various urban expansion patterns in the Hang-Jia-Hu Plain integrating geographic information systems, gradient analyses and landscape metrics. Our results demonstrate that the amount of urban land expanded to nearly four times that of the initial area during 1980-2010 and that $88 \%$ of new urban land was developed on paddy fields. Of the total area of paddy fields, paddy fields of level I accounted for $96 \%$. Moreover, various urban expansion styles differentially influenced the patterns of paddy fields. In autonomous expansion cities, sprawled urban land mainly occupied paddy fields in urban centers. However, the irregular expansion of passive expansion cities encroached on a number of paddy fields in the urban fringe where the landscape of urban patches and paddy fields was more complex and irregular in shape. Furthermore, the urbanization curve implies that future urbanization efforts will focus on the passive expansion cities, indicating that paddy fields still face the risk of disruption. We suggest that the boundary of urban development should be restricted,
\end{abstract}


permanent paddy reserves should be delimited, and ecologically oriented management systems that target paddy field protection should be implemented to ensure the sustainable development of this region. This work improved the understanding of the urbanization process that governed paddy fields dynamics, and provides a scientific basis for decision-making processes to achieve regional sustainability.

Keywords: paddy field patterns; urbanization; spatio-temporal dynamics; Hang-Jia-Hu Plain; sustainable development

\section{Introduction}

In China, urban growth has occurred at an unprecedented rate after the "Open Door Policy" (also called "the reform and opening-up policy", it is considered the turning point of Chinese economic development) in 1978. The urban proportion of the total population increased from $18 \%$ in 1978 to $50 \%$ in 2010 , and it is predicted to reach $60.3 \%$ by 2020 and exceed $80 \%$ by 2030 [1-4]. Rapid urban development has been accompanied by the large-scale conversion of cultivated land for development use, which has led to severe environmental issues, such as urban heat islands, air pollution, and urban flooding [5]. These adverse effects generate complex human-dominated landscapes, which significantly affect the functioning of local and global ecosystems as well as the services they provide to humans and other organisms [6,7].

The Hang-Jia-Hu Plain is one of the fastest developing areas of China. Paddy fields are the dominant type of farmland in this area, and they not only provide rice production but also serve multiple functions such as climate regulation, flood control, soil organic carbon storage, environmental protection, and the provision of an aesthetic landscape [8,9]. Rapid urbanization is one of the most serious problems affecting China's food security. It has degraded the landscapes of paddy fields and impacted their capacity to deliver ecosystem services [10-12]. Research has revealed that paddy fields have experienced sharp declines in rice production of $600 \mathrm{ton} / \mathrm{km}^{2} /$ year [13], and the value of their ecosystem services has decreased by 250 million yuan $/ \mathrm{km}^{2}$ [14].

Urban expansion is often triggered by socioeconomic factors and policy guidance, both of which are closely related to paddy soil loss. As a rapidly developing country, China has been experiencing unprecedented economic growth since the implementation of the reform and opening-up policy in 1978 [15]. In 1993, a fundamental social change occurred from state socialism toward a market economy, and the reform of fiscal decentralization was implemented in 1994. These changes were superimposed on the Hang-Jia-Hu Plain, which was considered as the preferential development area of China with substantial implementation of land acquisition and land leasing [16]. Consequently, the process of urbanization was markedly accelerated. With China's entry into the World Trade Organization (WTO) and its government's promotion of urbanization, the synergetic effects of global and local forces will continue to transform rural areas to urban areas in China [17].

Recently, geographic information systems (GIS) have been shown to be promising tools for monitoring urban sprawl in urbanizing regions $[15,18,19]$. Additionally, urbanization associated with land use changes and eco-environmental deterioration has attracted researchers worldwide [20-22]. 
Landscape metrics have been utilized in applied geographical studies regarding the sustainable development of urbanization [23,24]. The comprehensive application of landscape metrics and gradient analysis provides an effective way to understand the evolution of urban growth and to infer its potential effects on ecological processes $[25,26]$. However, most of the focused on metropolitan regions or cities of different sizes, and less attention has been given to the various expansion characteristics of cities and the spatiotemporal dynamic of paddy fields in response to the processes of urbanization with regards to sustainability.

Our study focuses on the Hang-Jia-Hu Plain, a fast-growing area of the Yangtze River Delta region. Hang-Jia-Hu Plain has also been considered one of the most important paddy bases in eastern coastal China for one thousand years. However, dramatic changes in land use occurred here along with the rapid economic growth of the post-reform period from 1980 to 2010. In this study, we integrate GIS, gradient analyses and landscape metrics to characterize the general trend of urbanization and distinguish the autonomous expansion mode and passive expansion mode in the Hang-Jia-Hu Plain from 1980 to 2010 . We then explore the pattern of paddy fields in response to different modes of urban expansion in different periods. Finally, we discuss the future development of urban areas and paddy fields and highlight the implications for sustainable development in this region.

\section{Materials and Methods}

\subsection{Study Area}

The Hang-Jia-Hu Plain is situated in the south of the Yangtze River Delta, and it is the largest accumulation plain in Zhejiang Province. This region contains a prefecture-level city (Jiaxing), two municipal districts (Yuhang, Nanxun), three county-level cities (Haining, Tongxiang, Pinghu) and three counties (Deqing, Haiyan, Jiashan) (Figure 1). It is characterized by a subtropical monsoon climate with an average annual temperature of $17.5{ }^{\circ} \mathrm{C}$ and annual precipitation of approximately 1139 mm. Paddy fields cover more than $50 \%$ of the Hang-Jia-Hu Plain. Dense river networks and low elevation are important elements of rice farming. The oldest rice cultivation practices date back to the Neolithic age (approximately 5300 years ago) in Yuhang, which is the cradle of Liangzhu culture. Therefore, the Hang-Jia-Hu Plain is considered one of the earliest locations of rice agriculture development and one of the most important paddy bases in eastern coastal China.

The Hang-Jia-Hu Plain has been experiencing rapid urbanization and economic development since 1979. According to the latest China Census, more than 5 million people were living in this region in 2010 , which is $28 \%$ more than in 1980. Similarly, the GDP of this region increased from 2.7 billion to 339.7 billion yuan over the last thirty years. Among the traffic hubs of Shanghai, Jiangsu and Zhejiang, the first expressway, from Shanghai to Hangzhou (G60), was opened to traffic in this area (Figure 1), and the total length of the expressway increased to $518.99 \mathrm{~km}$ by the end of 2010. Such rapid socio-economic development spurred intense urban sprawl, which encroached on a significant proportion of the paddy fields. Because of its important paddy field resources and rapidly urbanizing characteristics, the Hang-Jia-Hu Plain represents an ideal study area for the development of a remote sensing-based methodology for detecting regional spatiotemporal dynamic patterns caused by urban land sprawl. 


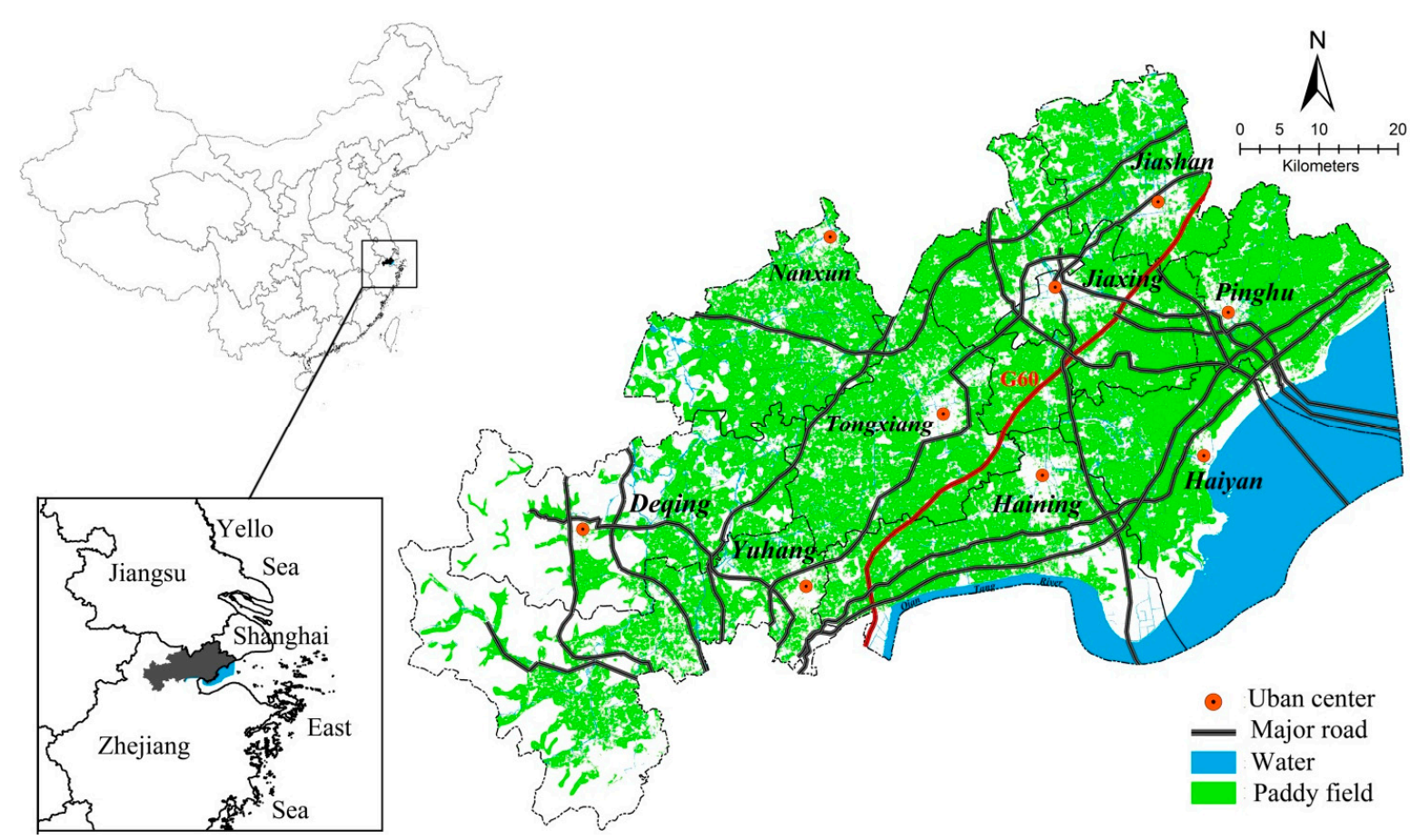

Figure 1. Location and administrative divisions of Hang-Jia-Hu Plain.

\subsection{Data Sources}

The comprehensive data used in this study included the following: (1) Digital land-use maps in 1980, 1990, 2000 and 2010 were provided by the Chinese Ministry of Environmental Protection. This dataset was constructed from the interpretation of remote-sensing data and field surveys and had a validated overall accuracy exceeding 90\%. (2) A 1:500000 digital map of farmland quality grade was provided by the Ministry of Land and Resources of China (MLR) and drawn from the new national land and resources investigation. (3) Demographic and socio-economic data in 1980, 1990, 2000 and 2010 were obtained from the local statistical bureau.

\subsection{Average Annual Rate of Urbanization Indicators}

The average annual rate we used to estimate the urbanization intensity is expressed as follows:

$$
R=\sqrt[n-1]{\frac{R_{2}}{R_{1}}}-1
$$

where $\mathrm{R}$ is the average annual change rate, $\mathrm{R}_{1}$ is the value at the start of the year, $\mathrm{R}_{2}$ is the value at the end of the year, and $n$ is the interval of the calculation period (in years).

\subsection{Spatiotemporal Analysis of the Urbanization Process}

The rapid urbanization process in China has resulted in the loss of cropland and biodiversity and increased water pollution and carbon emissions [27-29]. One of the most significant effects of rapid urbanization is the dramatic change to paddy fields in the Hang-Jia-Hu Plain, which are subjected to development. A gradient paradigm was employed in this study to monitor the spatial variance of 
urbanization and was used to detect those locations experiencing various types of urbanization in response to economic, social and political forces. Ten concentric belts radiating from the urban center to the outer edges were identified for nine cities in the Hang-Jia-Hu Plain. The geometric center of each town was determined from the built-up area at the beginning of the study (1980). For Jiaxing (the only prefecture-level city in study area), nearly $10 \mathrm{~km}$ were identified, radiating from the urban center to the fringe in 2010, so each buffer spanned $1 \mathrm{~km}$. For other towns, nearly $5 \mathrm{~km}$ were identified, radiating from the urban center to the fringe in 2010, the buffers spanned $0.5 \mathrm{~km}$. The gradient paradigm of each urban area was used to compare the differences among urbanization patterns in different regions.

To monitor the spatiotemporal dynamics and configuration of urban land expansion, we adopted two indicators: the urbanization intensity index (UII) and urban landscape shape index (ULSI). The UII indicates the spatiotemporal dynamics of urban sprawl and has been recognized as one of the main indicators involved in identifying the intensity of urbanization [30,31]. It is also significantly correlated with other widely used urbanization indices, such as population density and percentage of imperviousness. This index can be used to compare the spatial differentiation of the urban expansion per unit time to detect the way they evolve. The ULSI describes the complexity and irregularity of urban area shapes relative to the geometry of a circle (ULSI $\geq 1$ ), with higher values conveying a more complex urban shape [32,33]. The irregular pattern of urban area may lead to fragmented landscapes and increased the potential risks for other land. In our study, we measured the patches within each ring. These two metrics were used to assess different periods across nine regions, and they can aid in identifying the trends of urbanization processes.

The UII is defined as follows:

$$
U I I_{i}=\frac{A_{i, t+n}-A_{i, t}}{n \times W A_{i}} \times 100 \%
$$

where $U I I_{i}$ is the urban expansion intensity in the buffer $i ; A_{i, t+n}$ and $A_{i, t}$ are the urban area in the target buffer in year $t+n$ and year $t$, respectively; $n$ is the interval of the calculation period (in years); and $W A_{i}$ is the total area of spatial unit $i$.

The ULSI is expressed as follows:

$$
U L S I_{i}=\sum_{i=1}^{j}\left(\frac{0.25 P_{i j}}{\sqrt{A_{i j}}}\right)
$$

where $U L S I_{i}$ is the urban shape index of buffer $i$; and $P_{i j}$ and $A_{i j}$ are the perimeter and area, respectively, of urban patch $j$ in buffer $i$.

\subsection{Grading Paddy Field Quality}

According to the evaluation of Chinese farmland quality [34], farmland in Zhejiang province was divided into 21 grades (Grade 7 to Grade 27). In our study, we categorized these grades into three levels: Grades 7 through 13 were categorized as level III, Grades 14 through 20 as level II, and Grades 21 through 27 as level I (rice production: level I $>750$ ton $/ \mathrm{km}^{2} ; 660$ ton $/ \mathrm{km}^{2} \leq$ level II $\leq 750$ ton $/ \mathrm{km}^{2}$; 570 ton $/ \mathrm{km}^{2} \leq$ level III $<660$ ton $/ \mathrm{km}^{2}$ ). The digital land-use map was overlaid with a 1:500,000 digital map of farmland quality grade to determine the level of paddy field in ArcGIS 10.0. 


\subsection{Dynamic Changes of Paddy Fields during the Urbanization Process}

Urbanization not only reduces the number of paddy fields but also is destructive to the structure of paddy fields. This trend of destruction is caused, at least in part, by the high population density and advanced economic development in eastern coastal China [15,35,36]. Landscape metrics are effective at externalizing complex spatial landscapes. To characterize the spatiotemporal dynamic patterns and configuration of paddy fields in response to urbanization, we used the percentage of the paddy field landscape (PLAND) and the paddy field landscape shape index (PLSI), respectively. PLAND is a general index that depicts landscape dominance in each unit, and it is closely related to food security and thus sustainability in our study. The PLSI describes the complexity and irregularity of the paddy field shape (the formula is the same as for ULSI). A change in the PLSI indicates the degree of disturbance to the paddy field structure as a result of urban sprawl.

The PLAND is defined as follows:

$$
\operatorname{PLAND}_{i}=\frac{\sum_{i=1}^{j} a_{i j}}{W A_{i}} \times 100
$$

where $P L A N D_{i}$ is the percentage of paddy field landscape in the buffer $i, a_{i j}$ is the paddy field area in the buffer $i$, and $W A i$ is the total area of spatial unit $i$.

\section{Results}

\subsection{General Process of Urbanization}

Table 1 indicates that economic growth was significant over the last three decades (1980-2010), with an annual increase rate of $18.09 \%$, indicating steady population growth. The growing economy resulted in the large spatial expansion of cities in the Hang-Jia-Hu Plain. The urbanized areas increased from $435.46 \mathrm{~km}^{2}$ in 1980 to $1616.22 \mathrm{~km}^{2}$ in 2010 . Spatial patterns are shown in Figure 2. With a net increase of $1146.26 \mathrm{~km}^{2}$, developed land occupied $20.3 \%$ of the entire region in 2010 .

Table 1. Urbanization indicators between 1980 and 2010 for the Hang-Jia-Hu Plain area.

\begin{tabular}{cccccccc}
\hline & $\mathbf{1 9 8 0}$ & $\mathbf{1 9 9 0}$ & $\mathbf{2 0 0 0}$ & $\mathbf{2 0 1 0}$ & $\begin{array}{c}\text { Change Rate } \\
\text { between 1980 } \\
\text { and 1990 (\%) }\end{array}$ & $\begin{array}{c}\text { Change Rate } \\
\text { between 1990 } \\
\text { and 2000 (\%) }\end{array}$ & $\begin{array}{c}\text { Change Rate } \\
\text { between 2000 } \\
\text { and 2010 (\%) }\end{array}$ \\
\hline $\begin{array}{c}\text { Gross domestic } \\
\text { product (billion yuan) } \\
\text { Total population } \\
\text { (million) }\end{array}$ & 2.74 & 12.44 & 77.07 & 339.78 & 18.32 & 22.49 & 23.20 \\
$\begin{array}{c}\text { Urban area }\left(\mathrm{km}^{2}\right) \\
\text { (n) }\end{array}$ & 435.46 & 4.46 & 4.55 & 5.26 & 1.43 & 0.23 & 1.48 \\
\hline
\end{tabular}



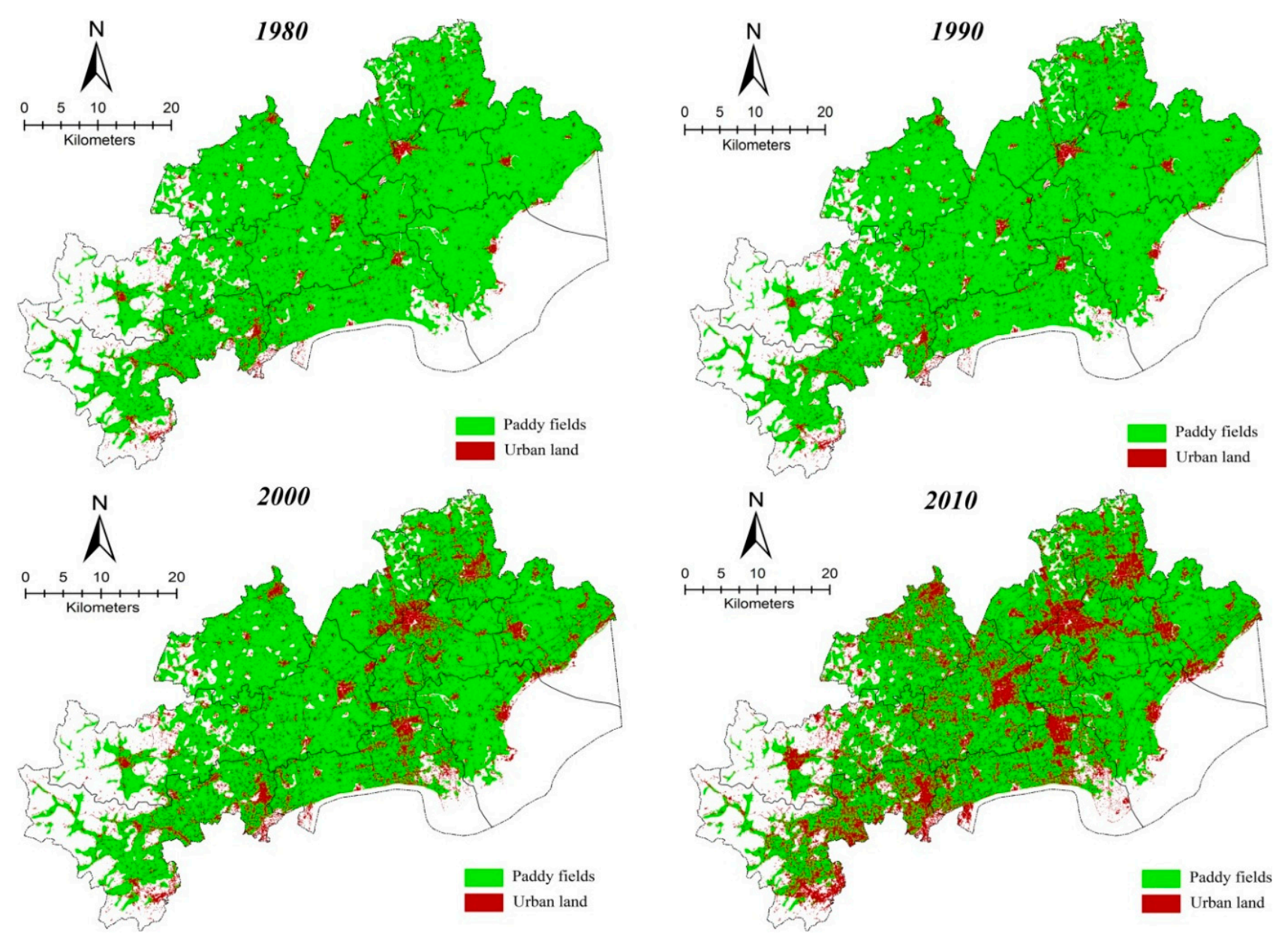

Figure 2. Spatial patterns of build-ups and paddy fields in 1980, 1990, 2000, and 2010 in the Hang-Jia-Hu Plain.

\subsection{Dynamic Changes of Paddy Fields}

\subsubsection{Quality Grades of Paddy Fields in the Hang-Jia-Hu Plain}

As shown in Table 2, paddy fields of level II were the predominant type in Zhejiang Province; however, level I was widely distributed in the Hang-Jia-Hu Plain, which accounted for approximately $47 \%$ of the total area of level I fields in Zhejiang Province. The spatial patterns of these paddy fields are shown in Figure 3. These results indicate that excessive urban expansion encroached upon large areas of high-quality paddy fields.

Table 2. Quality grades of paddy fields in the Hang-Jia-Hu Plain.

\begin{tabular}{|c|c|c|c|c|c|c|}
\hline & \multicolumn{2}{|c|}{ Level I } & \multicolumn{2}{|c|}{ Level II } & \multicolumn{2}{|c|}{ Level III } \\
\hline & Area $\left(\mathbf{k m}^{2}\right)$ & (\% of total) & Area $\left(\mathbf{k m}^{2}\right)$ & (\% of total) & Area $\left(\mathbf{k m}^{2}\right)$ & (\% of total) \\
\hline Zhejiang Province & 6375.96 & 31.40 & 11144.04 & 54.90 & 2784.13 & 13.70 \\
\hline Hang-Jia-Hu Plain & 3009.31 & 96.17 & 123.24 & 3.93 & 0.00 & 0.00 \\
\hline
\end{tabular}




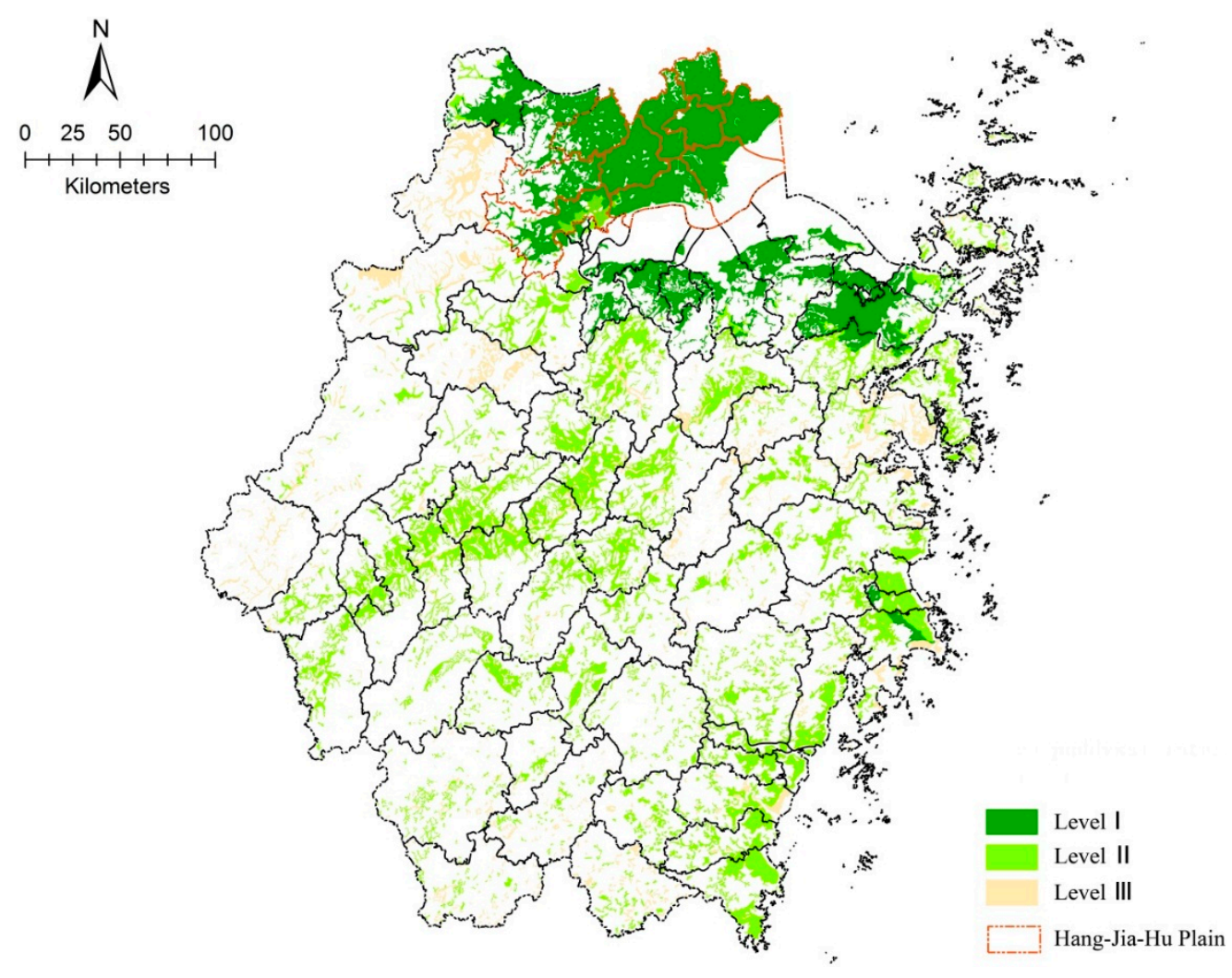

Figure 3. Different levels of paddy field patterns in Zhejiang Province.

\subsubsection{Dynamic Changes of Paddy Fields in Response to Urbanization}

Studying the spatial and temporal heterogeneity of the changes in paddy field losses at the administrative level allowed us to identify the rapid- and slow-loss areas and recommend different protection policies. The largest losses occurred in Jiaxing, Tongxiang, and Jiashan, where more than 95\% of new urban areas were converted from paddy fields (Table 3 ). In general, $88 \%$ of new urban areas were converted from paddy fields in the Hang-Jia-Hu Plain from 1980 to 2010. Cities are generally situated in plains areas with rich water resources and suitable lands for agriculture. Figure 4 shows that new urban areas tended to be clustered around existing cores; therefore, paddy soil losses were first observed at the periphery of the developed urban area. This phenomenon was previously demonstrated in other regions of China by Pan and Zhao [35]. We also found that almost $72 \%$ of the loss was distributed in the buffer zone $5 \mathrm{~km}$ from the urban center (10 km from the urban center in Jiaxing).

Table 3. Urban expansion and paddy field loss across the Hang-Jia-Hu Plain.

\begin{tabular}{|c|c|c|c|c|}
\hline & \multirow{2}{*}{ Period } & \multirow{2}{*}{ New Urban Area $\left(\mathrm{km}^{2}\right)$} & \multicolumn{2}{|c|}{ New urban Area Converted Form Paddy Fields } \\
\hline & & & Area $\left(\mathbf{k m}^{2}\right)$ & (\% of New Urban Area) \\
\hline \multirow{3}{*}{ Yuhang } & $\mathrm{T} 1$ & 2.57 & 2.07 & 80.54 \\
\hline & $\mathrm{T} 2$ & 50.67 & 35.92 & 70.89 \\
\hline & $\mathrm{T} 3$ & 151.54 & 120.07 & 79.23 \\
\hline \multirow{3}{*}{ Deqing } & $\mathrm{T} 1$ & 1.24 & 0.83 & 66.94 \\
\hline & $\mathrm{T} 2$ & 20.01 & 12.81 & 64.02 \\
\hline & T3 & 66.63 & 49.18 & 73.81 \\
\hline
\end{tabular}


Table 3. Cont.

\begin{tabular}{|c|c|c|c|c|}
\hline & \multirow{2}{*}{ Period } & \multirow{2}{*}{ New Urban Area $\left(\mathrm{km}^{2}\right)$} & \multicolumn{2}{|c|}{ New urban Area Converted Form Paddy Fields } \\
\hline & & & Area $\left(\mathrm{km}^{2}\right)$ & (\% of New Urban Area) \\
\hline \multirow{3}{*}{ Nanxun } & $\mathrm{T} 1$ & 0.98 & 0.55 & 56.12 \\
\hline & $\mathrm{T} 2$ & 19.89 & 17.42 & 87.58 \\
\hline & $\mathrm{T} 3$ & 95.13 & 87.96 & 92.46 \\
\hline \multirow{3}{*}{ Haining } & $\mathrm{T} 1$ & 6.67 & 4.75 & 71.21 \\
\hline & $\mathrm{T} 2$ & 82.23 & 69.99 & 85.11 \\
\hline & $\mathrm{T} 3$ & 79.46 & 64.75 & 81.49 \\
\hline \multirow{3}{*}{ Haiyan } & $\mathrm{T} 1$ & 7.51 & 4.79 & 63.78 \\
\hline & $\mathrm{T} 2$ & 24.53 & 20.44 & 83.33 \\
\hline & $\mathrm{T} 3$ & 25.56 & 23.07 & 90.26 \\
\hline \multirow{3}{*}{ Jiashan } & $\mathrm{T} 1$ & 15.29 & 14.54 & 95.09 \\
\hline & $\mathrm{T} 2$ & 39.01 & 38.27 & 98.10 \\
\hline & $\mathrm{T} 3$ & 40.09 & 40.77 & 96.86 \\
\hline \multirow{3}{*}{ Pinghu } & $\mathrm{T} 1$ & 15.52 & 14.06 & 90.59 \\
\hline & $\mathrm{T} 2$ & 46.47 & 44.26 & 95.24 \\
\hline & $\mathrm{T} 3$ & 26.41 & 23.37 & 88.49 \\
\hline \multirow{3}{*}{ Tongxiang } & $\mathrm{T} 1$ & 1.21 & 0.98 & 80.99 \\
\hline & $\mathrm{T} 2$ & 31.27 & 30.29 & 96.87 \\
\hline & $\mathrm{T} 3$ & 126.24 & 122.38 & 96.94 \\
\hline \multirow{3}{*}{ Jiaxing } & $\mathrm{T} 1$ & 14.57 & 14.04 & 96.36 \\
\hline & $\mathrm{T} 2$ & 100.30 & 98.80 & 98.50 \\
\hline & $\mathrm{T} 3$ & 87.76 & 86.33 & 98.37 \\
\hline
\end{tabular}

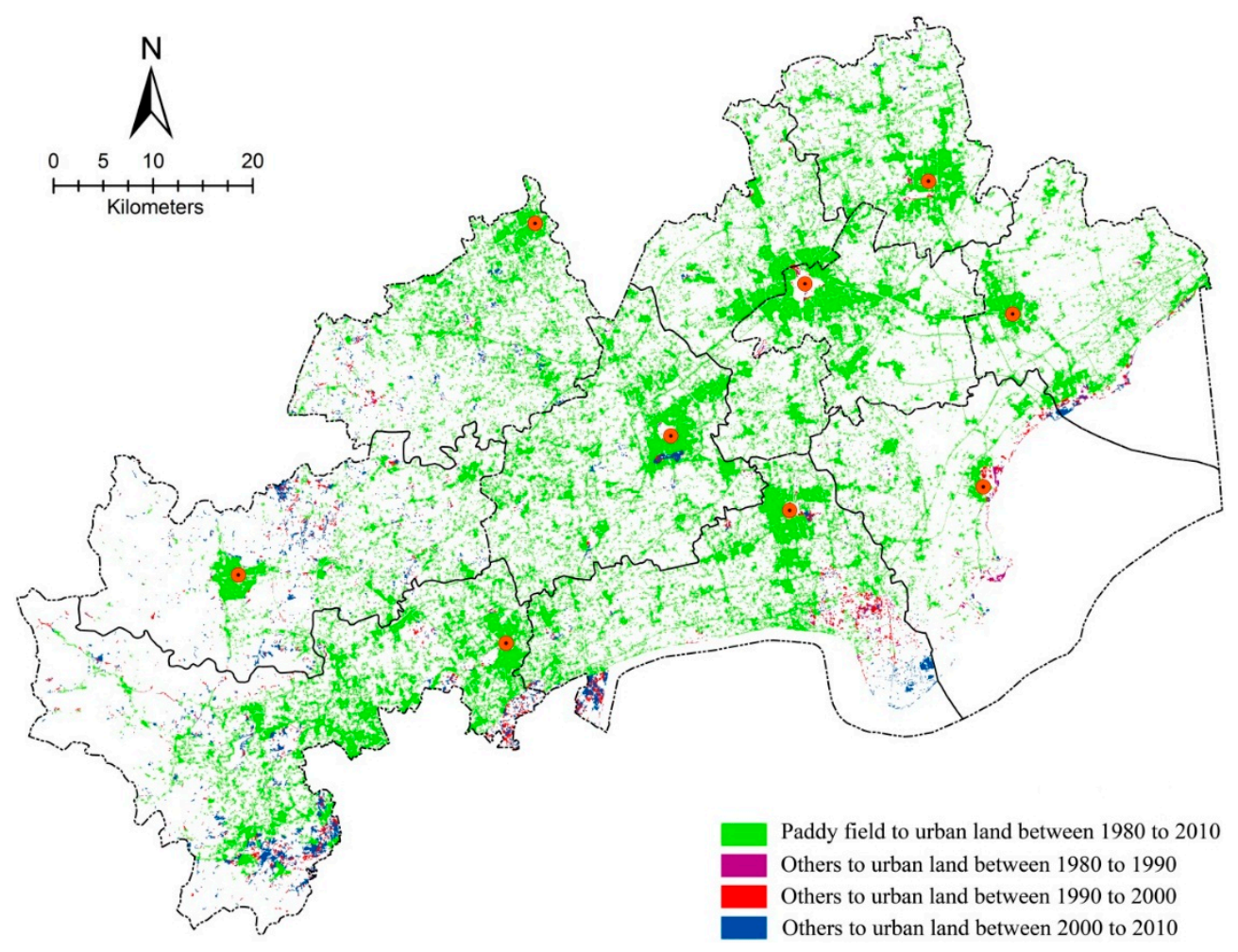

Figure 4. Spatial patterns of paddy fields and non-paddy fields encroached by increased urban land in the Hang-Jia-Hu Plain from 1980 to 2010. 


\subsection{Spatiotemporal Dynamic Patterns of Urban Growth in the Hang-Jia-Hu Plain}

Each city had an equivalent-sized buffer zone, which provided insights into the spatial patterns of urban growth within and around the cities during the three time periods. Based on the UII changes of ten concentric belts, we defined the region from belt 1 to the UII peak as the urban core, and the region after the peak was considered as a transitional zone. The following area that levels off was called the urban fringe. For example, in Deqing in T3 (Figure 5), belts 1-4 were considered as the urban core, belts $4-8$ were considered as the transition zone, and belts $8-10$ were considered as the urban fringe.

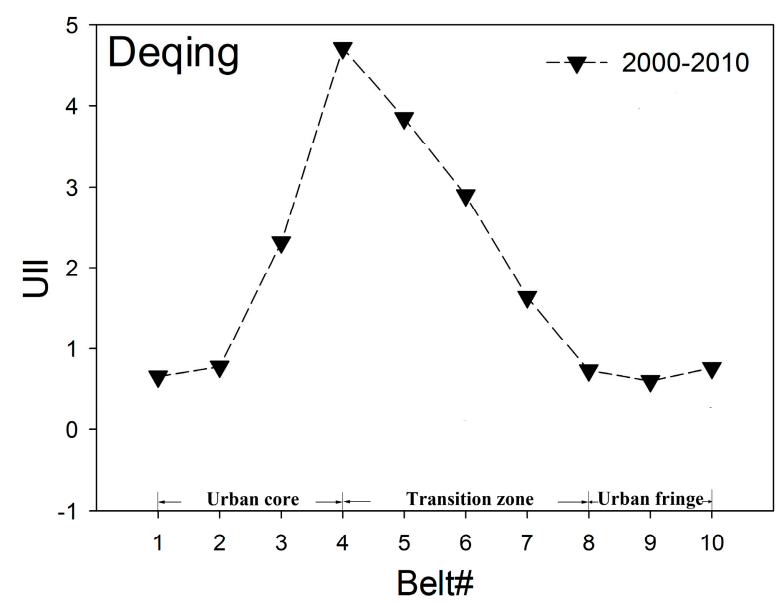

Figure 5. An example of the urban core, transition zone and urban fringe regions.

Nine cities were divided into autonomous expansion mode and passive expansion mode based on the different patterns of urban sprawl, with Deqing, Pinghu, and Haiyan the autonomous expansion cities and Jiaxing, Haining, Tongxiang, Yuhang, Nanxun, and Jiashan as the passive expansion cities. Autonomous expansion cities expanded independently and clearly exhibited the full structure consisting of the urban core, transition zone and urban fringe (Figure 6b). In comparison, the expansion pattern of passive expansion cities was irregular and did not exhibit an increasingly regulated urban core as well as transitional zones and urban fringe areas (Figure 6c).

In the urban core, the UII of the autonomous expansion cities increased with an increase in buffer distance (Figure 7a). For the transition zones, the UII sharply decreased; it then decreased more gradually in the urban fringe. In T1, the urban core for Deqing was not obvious, whereas the urban cores in Pinghu and Haiyan were composed of belts 1-3 and belts 1-2, respectively. The urban core for Deqing was belts 1-3 in T2 and expanded to belts 1-4 in T3, whereas the urban cores for Pinghu and Haiyan increased to belts $1-4$ and belts $1-3$ in T2, respectively, and then to belts $1-5$ and belts $1-4$ in T3, respectively. The ULSI of the autonomous expansion cities reached peak values when the UII reached peak values in all three periods (Figure $7 b$ ). With increasing distance from the urban core, the ULSI declined with increased buffer distance. For the urban fringe, the ULSI increased gradually with increased buffer distance because of fragmentary expansion. The data revealed that urban patches were more compact in the urban core and more irregular at the urban fringe areas over time. These results indicated that autonomous expansion cities have increasingly regulated urban cores as well as transitional zones and urban fringes. During the thirty-year period under study, the development of Deqing, Pinghu and Haiyan was complete and mature. 

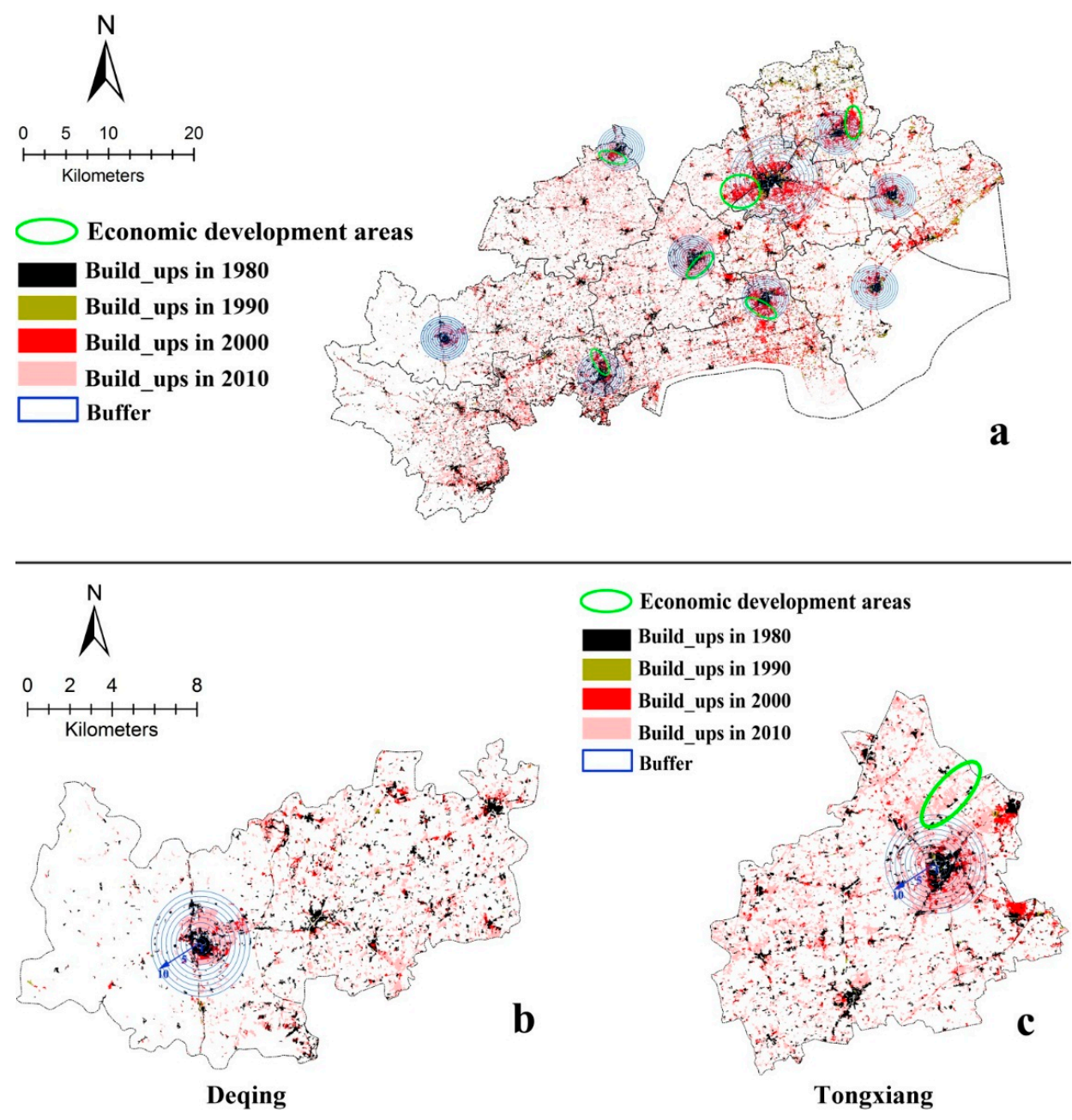

Figure 6. The layout of the concentric belts: (a) the buffer zones of the Hang-Jia-Hu Plain; (b) an example of an autonomous expansion city; and (c) an example of a passive expansion city.

In contrast, the UII in the urban cores of the passive expansion cities did not exhibit a particular pattern of change over time (Figure 7c). For the transition zones, the UII decreased gradually and then maintained a high value in urban fringes. The peak value of the UII in Jiaxing, Haining, Yuhang, and Jiashan was highest in T2, whereas the UII experienced a more gradual change in T3, with a peak value maintained in two belts, suggesting that the intensity of urban expansion occurred in $\mathrm{T} 2$, and the large-scale expansion area emerged in T3. However, the peak value of the UII in Tongxiang and Nanxun was highest in T3. The UII of Tongxiang increased dramatically from belt 3 in T3, suggesting that urban expansion was intense and widespread during this period. The ULSI of the passive expansion cities increased from the urban core to the urban fringe, indicating that urban patches were more complex and irregular at the urban edge (Figure 7d). These results indicated that passive expansion cities have irregular expansion patterns that were largely caused by the large-scale economic development areas $\left(\geq 10 \mathrm{~km}^{2}\right)$ at the urban fringe (Figure 6a). Thus, in these cases, the development of economic development areas extended the urban boundaries and encroached on many paddy fields in this region. 
a

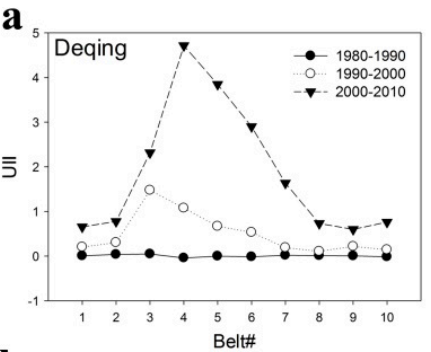

b

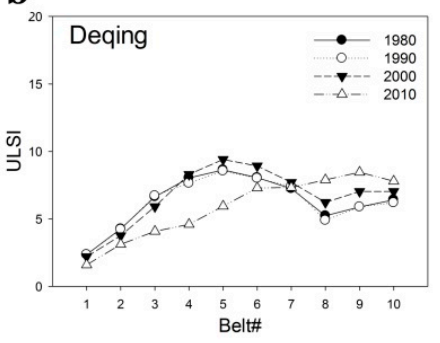

c
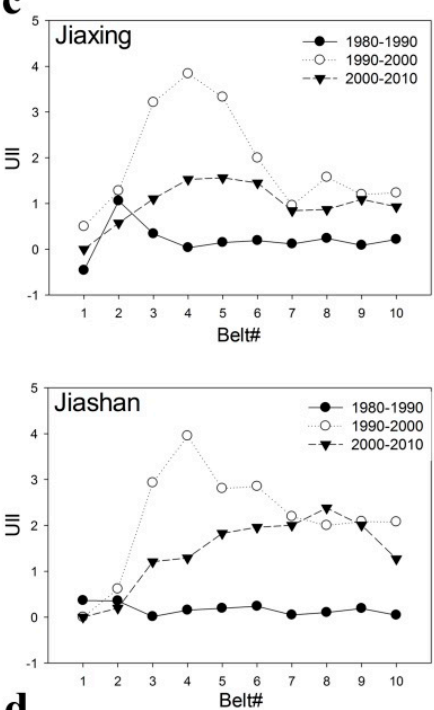

d
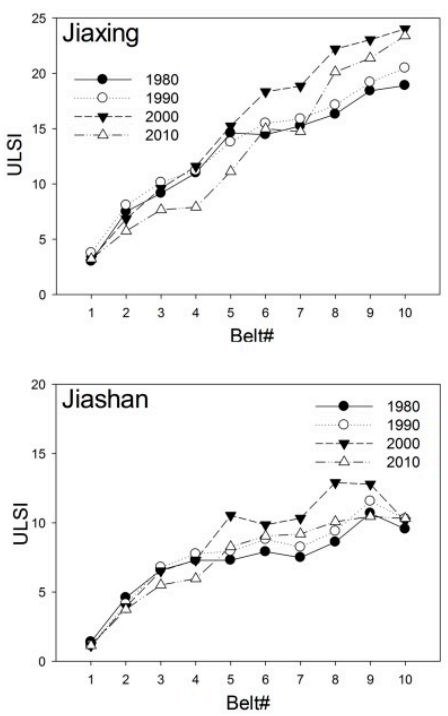
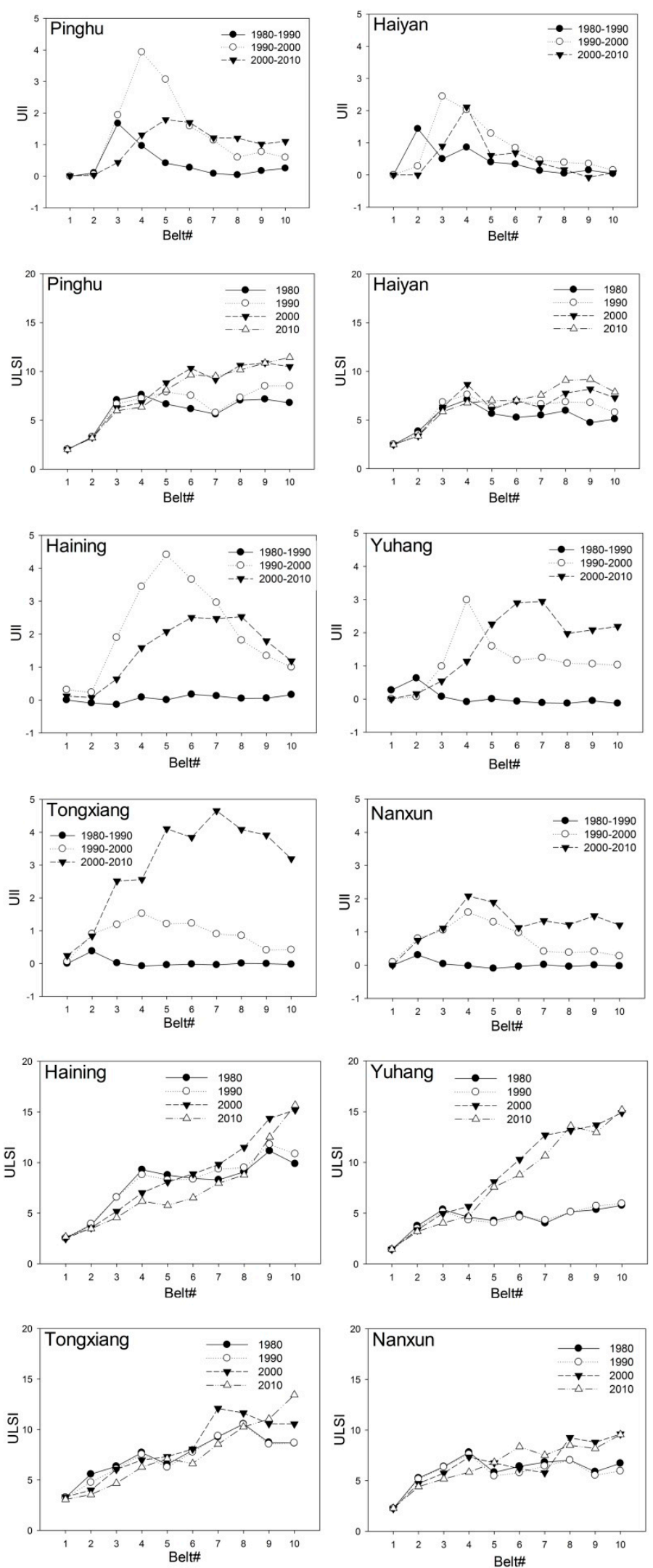

Figure 7. Gradient paradigm of urban growth patterns in each belt for each period: (a) UII (urbanization intensity index) changes of autonomous expansion cities; (b) ULSI (urban landscape shape index) changes of autonomous expansion cities; (c) UII changes of passive expansion cities; and (d) ULSI changes of passive expansion cities. 


\subsection{Spatiotemporal Dynamic Patterns of Paddy Fields in Response to Urban Growth}

Autonomous expansion cities: The PLAND of paddy fields in Deqing, Pinghu, and Haiyan indicated that paddy fields continuously decreased in all concentric belts from 1980 to 2010 and that the largest decline occurred in urban cores (Figure 8a). In the transitional zones, the gradual increase in the PLAND of paddy fields combined with the gradual decrease of the UII suggests that the paddy fields were encroached primarily by the regular growth of urban cores. A slight increase of PLAND in the urban fringe indicates that paddy field areas were not occupied continuously. Changes in the pattern of the PLSI within the transitional zone were consistent with the PLAND changes (Figure 8b); however, the PLSI appeared jagged in the suburbs, indicating that the sporadic expansion of the suburbs increased the fragmentation of the paddy fields to some extent.

Passive expansion cities: The changes of the PLAND and PLSI of paddy fields in Jiaxing, Haining, Yuhang, Jiashan, Tongxiang and Nanxun were also irregular because of irregular urban expansion patterns (Figure 8c). The decreased PLAND of the paddy fields was combined with an increase in the UII in each city. Figure 5 indicates that the PLAND in Jiaxing, Haining, Yuhang, Jiashan was reduced significantly in T2 and that intense changes occurred in Tongxiang and Nanxun in T3. Compared with the autonomous expansion cities, the PLAND in the extended passive cities declined continuously with increasing buffer distance, leading to a consistent increase in PLSI and a peak at an urban fringe belt (Figure 8d). This finding suggests that the economic development areas located in the suburbs encroached many paddy fields, and the risk of their future reduction was obvious.
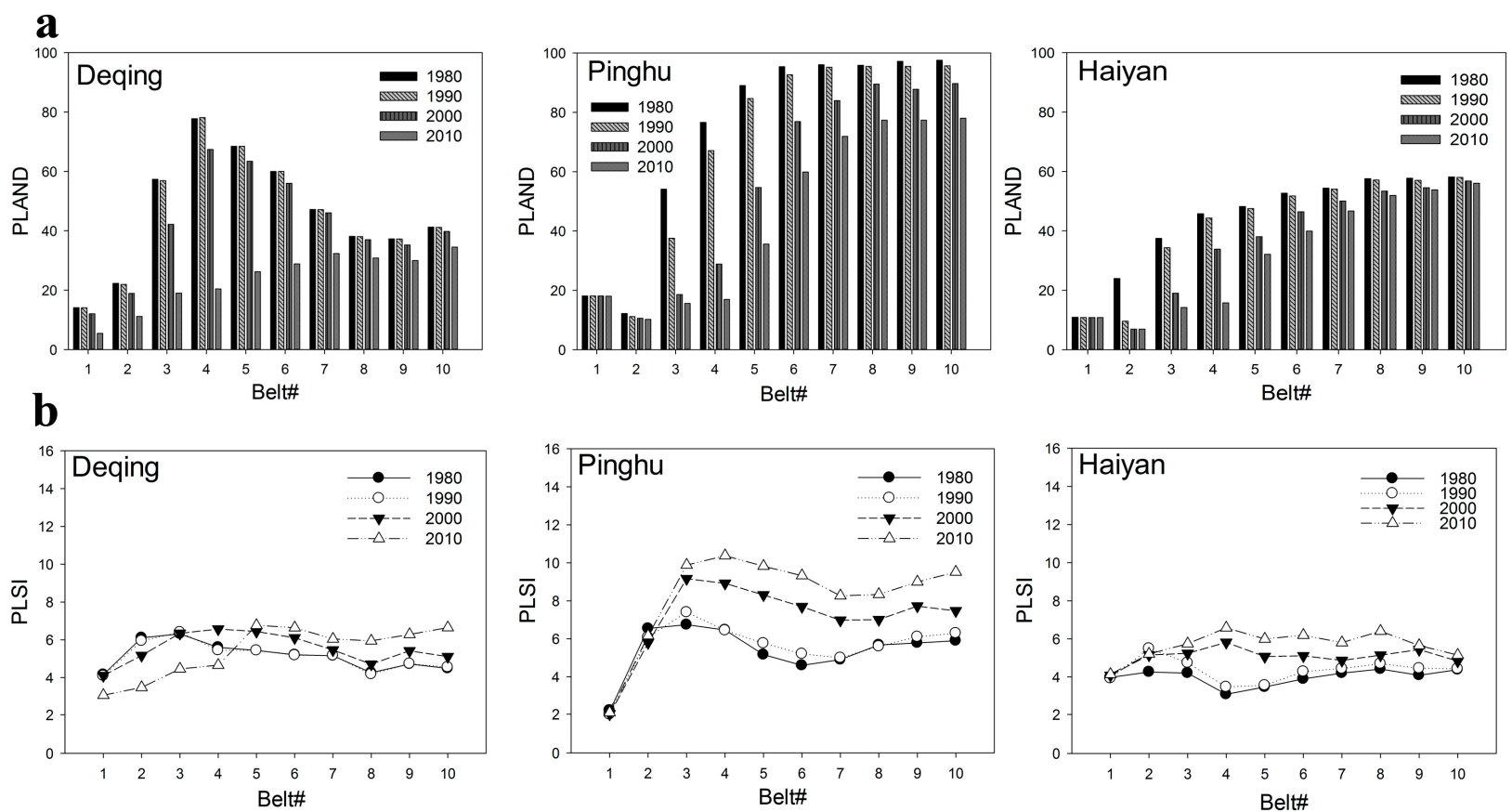

Figure 8. Cont. 

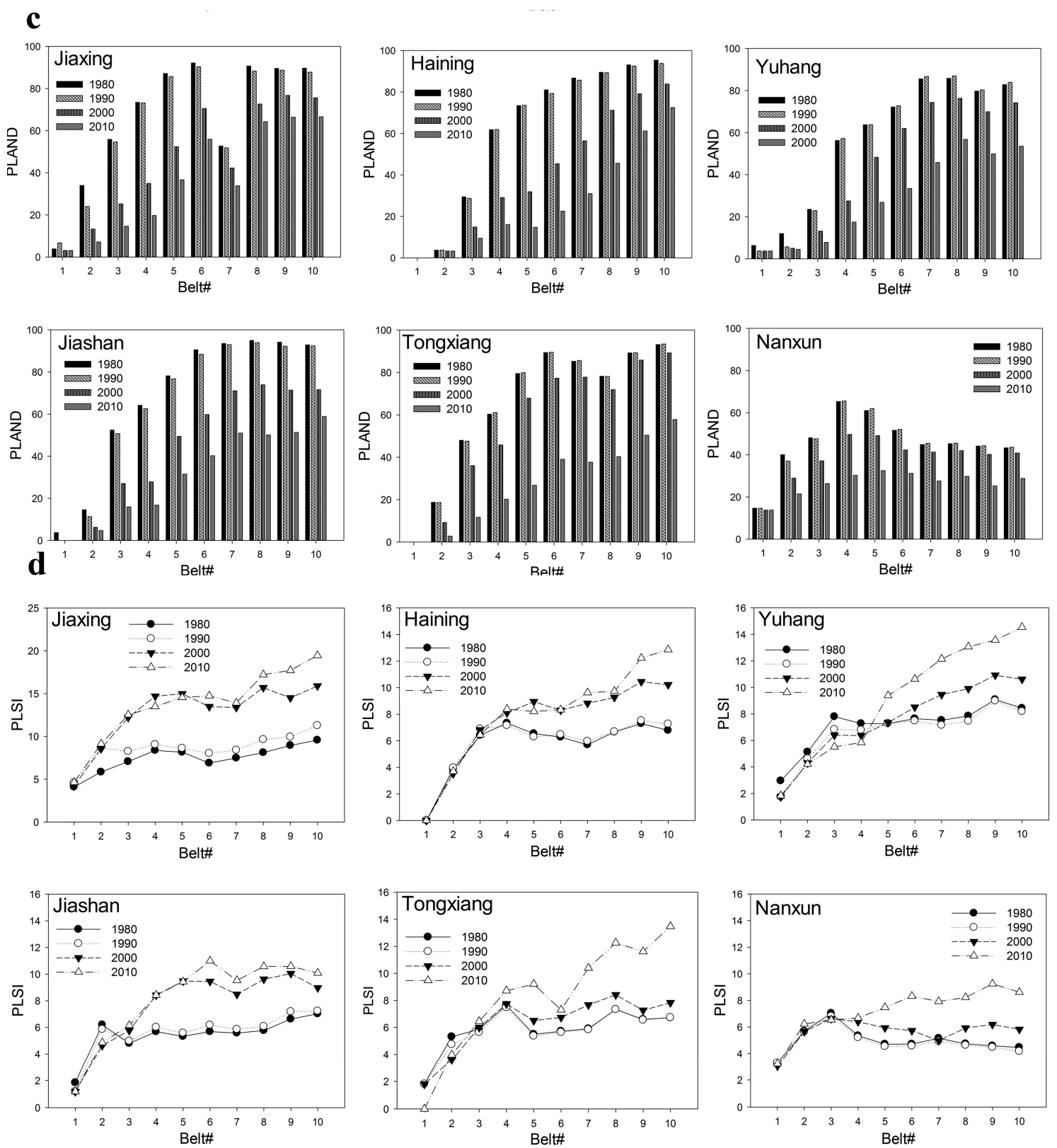

Figure 8. Gradient paradigm of paddy fields patterns in each belt for each period: (a) PLAND (percentage of the paddy field landscape) changes of autonomous expansion cities;

(b) PLSI (paddy field landscape shape index) changes of autonomous expansion cities; (c) PLAND changes of passive expansion cities; and (d) PLSI changes of passive expansion cities.

\section{Discussions}

\subsection{Driving Forces of Urban Expansion}

During last three decades, the GDP of the Hang-Jia-Hu Plain increased by more than 125 times, and the urban built-up area expanded to nearly four times the initial area, which far exceeds the nation's standard of $80-120 \mathrm{~m}^{2} /$ person. Several studies have shown that the trajectories of urbanization reflect economic development, demographic change and policy scenarios [15,19,37]. As expected, we found that the GDP and population had a strong relationship with urban expansion from 1980 to 2010 
(Figure 9). However, economic development and urban expansion are characterized by a typical government-driven model in China. Since 1978, opening up the country to a greater diversity of investments has shifted the planned economy to a socialist market economy [38]. In 1987, land reform allowed land leasing and charging between either the state and the user or between users [20]. Moreover, urban development guidelines were promulgated by the State Council of China in the 1980s, which strictly controlled the scale of big cities, rationally developed medium cities, and actively encouraged the development of small cities. Thus, the cities and countries in the Hang-Jia-Hu Plain witnessed considerable growth due to the prosperity of private enterprises and house construction between 1980 and 1990 (Figure 2). After the reform of fiscal decentralization in 1994, the central government substantially increased the financial contribution required from local governments. To extract as much extra-budgetary revenue as possible, local governments implement substantial measures to attract investments [32]. From 1990 to 2000, there were nine economic development zones established by various levels of local government in the Hang-Jia-Hu Plain, and the first expressway, from Shanghai to Hangzhou (G60), was opened up to traffic in this area (Figure 1). Development of the land for industrial, infrastructural and commercial purposes had a profound influence on urban sprawl. With China's entry into the World Trade Organization (WTO), the synergetic effects of global and local forces on property markets greatly promoted urban expansion and intensified paddy field losses in urban fringes between 2000 and 2010 (Figure 2). Meanwhile, "Opinions on Promoting and reforming small town household registration management system" was ratified by the State Council in 2001 and encouraged farmers to move into small towns. At this time, the household registration system was gradually being liberated. The growth of the urban population increases the demands for living space, employment, transportation land, common green belt, and other factors, thus effectively promoting the process of urban expansion.
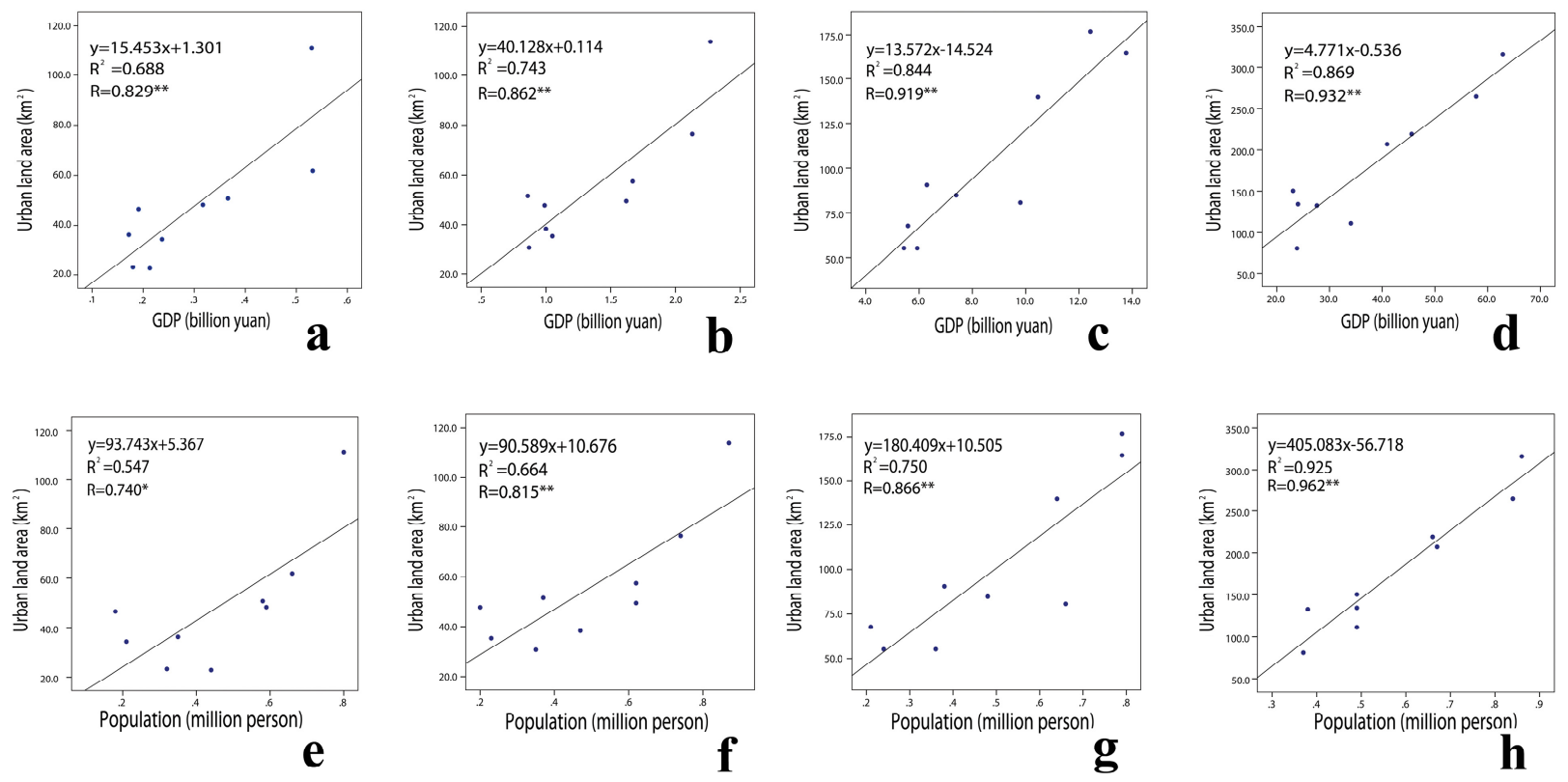

Figure 9. Linear regression between urban land area and socio-economic indicators: Linear regression between urban land area and GDP for (a) 1980; (b) 1990; (c) 2000; and (d) 2010; and linear regression between urban land area and POP for (e) 1980; (f) 1990; (g) 2000; and (h) 2010 . 
In addition, in the traffic hubs of Shanghai, Jiangsu and Zhejiang, highways are the important driving force of urban expansion in the Hang-Jia-Hu Plain. By the end of 2010, the total length of the expressway increased to $518.99 \mathrm{~km}$. The accelerated construction of highways can stimulate urban expansion along highways corridors, and the highways serve as conduits for the flow of goods and services [39,40]. Regarding the positive impact of expressway on urban expansion, this result corroborates the close positive association between mileage of expressway and urban land area (Figure 10).
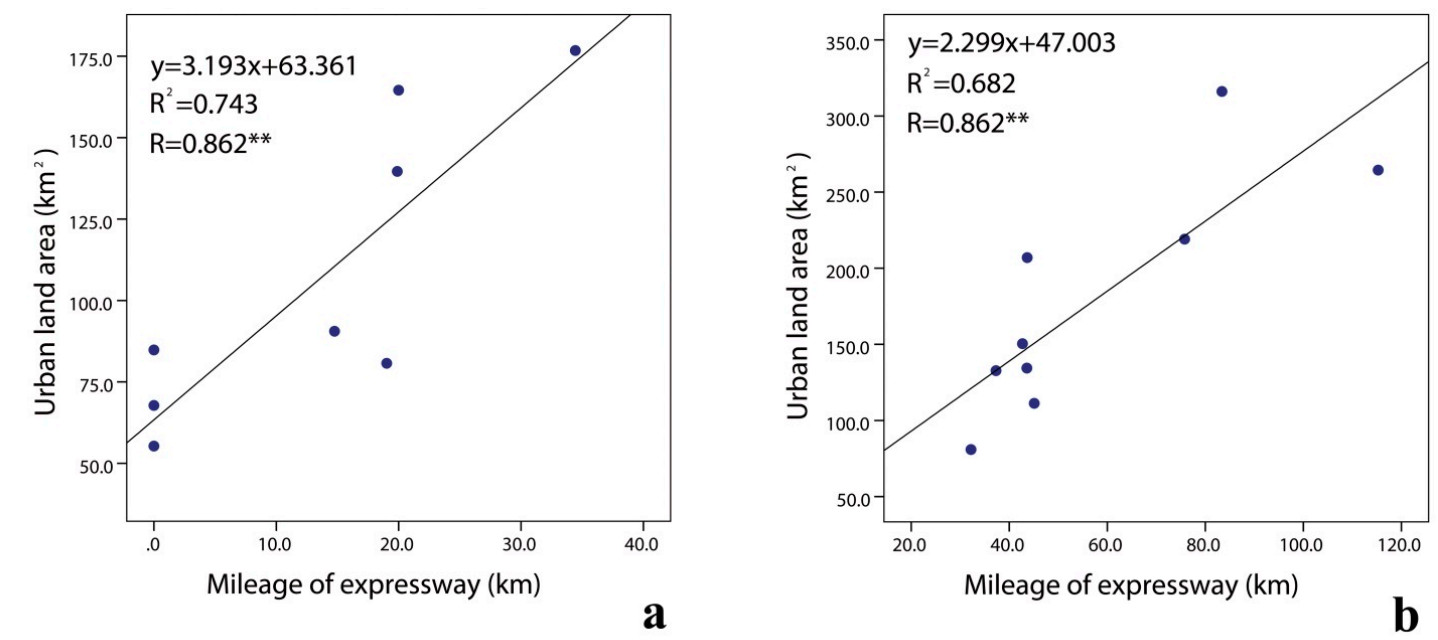

$* p<0.05 ; * * p<0.01$

Figure 10. Linear regression between urban land area and mileage of expressway for (a) 2000 and (b) 2010 .

\subsection{Spatial Features of Urban Growth and Their Impacts on Paddy Field Patterns}

Urban expansion of the Hang-Jia-Hu Plain was highly concentrated between 1980 and 2010. City seeds began to generate in T1, expanded in T2 and combined in T3. In accordance with the characteristics of urban expansion, nine cities were divided into autonomous expansion cities and passive expansion cities based on the UII. Similar results were found for Shanghai: the sub-cities of Shanghai were classified into four categories according to their performance in urban land use expansion (i.e., Standard, Passive, Steady and Irregular types) [41]. Autonomous expansion cities developed regularly and compactly. Alternatively, due to the geographical advantage and development policy, each passive expansion city had established large-scale economic development zones $\left(\geq 10 \mathrm{~km}^{2}\right)$ by the end of 2010 (Figure 6a). The total planning area of these economic development zones is $396 \mathrm{~km}^{2}$, and GDP output is nearly 0.9 billion yuan $/ \mathrm{km}^{2}$. The drastic growth of GDP drove the excessive spread of passive expansion cities. In passive expansion cities, the continuously increasing ULSI implies that the urban boundary become more complex in shape. Several recent studies have also found similar characteristics in expanded urban areas $[39,42,43]$. Two possible reasons could explain the more irregular shape. One potential reason is that all passive expansion cities had opened to expressway traffic before 2000, and expansion of these roads created a new spatial framework for urban land use. A second potential reason is that the simultaneous development of economic development areas and new residential areas contributed to this framework and consolidated the "pancake" or "carpet" style of urban expansion. 
Despite the proven benefits of paddy fields, widespread losses of these agricultural lands to development have been reported in American and European cities [10,44]. In our study area, 88\% of new urban land areas were converted from paddy fields between 1980 and 2010 (Table 3). Similar to the Jing-Jin-Ji region, of all the new urban land, approximately $74 \%$ was converted from agricultural land [18]. According to IRRI [45], average rice production in China is approximately $650 \mathrm{ton} / \mathrm{km}^{2}$; thus, the paddy fields of levels I and II are all high-production fields. As the major paddy bases in eastern coastal China, these two high-quality paddy soil types were widely distributed in the Hang-Jia-Hu Plain (Table 2). However, large amounts of paddy fields with high production were encroached by excessive urban expansion. Our results support the idea that farmland of the highest quality is always the first victim of urban expansion [46]. A substantial reduction of paddy fields of high quality lead to a decline in rice production of approximately 750,000 ton in last three decades and impaired the landscape of paddy fields.

Sprawled urban land reduced almost all paddy fields in urban cores in both autonomous expansion cities and passive expansion cities, resulting in a decline in PLAND as the UII increased (Figures 7 and 8). However, passive expansion cities witnessed a dramatic reduction in paddy fields in the urban fringe. Due to the spatial association between paddy fields and urban patches, cities expanded at the expense of the surrounding paddy fields (Figure 4). Meanwhile, well-drained land with little slope is generally favored for both rice cultivation and urban development [47]. In addition, increasing ULSI was accompanied with an increase in PLSI, indicating that the irregular pattern of build-up area can give rise to more irregular and unstable patches of paddy fields. These fragmented landscapes of paddy fields can potentially increase risks, such as those associated with pest control and land management [19]. Moreover, once the paddy field structure is destroyed, it can no longer contribute to the amelioration of the environmental impacts of urbanization (e.g., climatic change, erosion, water pollution) [12]. Thus, the sustainability of the Hang-Jia-Hu Plain has been greatly affected.

These transformations to the paddy fields of these cities were subject to economical focus by local and central governments. Since reformation and opening in 1978, the growth of the GDP greatly spurred urban construction. At the early stage, the shifts of land use practices lacked unified guidance. Thus, the "pancake" style of urban expansion driven by the effects of district industrial parks and expressways has caused large-scale losses of high-quality paddy fields, sometimes directly but often indirectly. In addition, rapid urban development encouraged an increasing number of farmers to abandon their farmlands to work and enjoy a life in urban areas. Therefore, large amounts of abandoned paddy fields were converted to development use.

\subsection{Future Implications for Sustainable Development in the Hang-Jia-Hu Plain}

The loss of paddy fields is one of the most serious problems causing the decline in food production, which poses a great threat to world food security. Moreover, paddy fields perform multiple crucial functions that ameliorate the environmental effects of urbanization, and if they are converted to urban use, their full range of environmental functions will be lost [48]. Several recent studies have reported that many countries made their great efforts to protect the paddy fields and avoid environmental degradation. In Indonesia, new paddy fields will be established in fluviomarine areas to avoid environmental degradation in tidal areas [49]. Biodiversity-conscious rice farming has been promoted 
by collaborations among farmers, consumers and governments in Japan [9]. However, rapid urbanization in the Hang-Jia-Hu Plain has led to land-use conflicts and related environmental degradation, which have caused concerns worldwide. This situation was acknowledged by the central government at the beginning of the fast growing period. The Land Act was revised in 1998 to control land expansion and the "basic farmland protection areas regulation" policy was adopted thereafter to protect paddy fields from being converted into developed land [35]. However, deficient systematic considerations, low public awareness and support, and insufficient land resource utilization and management have led to the notable loss and waste of paddy fields. In 2014, the Ministry of Land and Resources of China (MLR) decided to delimit the boundary of urban development in several large cities to control the accelerated urban sprawl and to protect farmland from transforming into build-up area. Although the cities and countries are all medium or small cities (except Yuhang, which became a district of Hangzhou in 2001) in the Hang-Jia-Hu Plain, the excessive amounts of built-up land had already encroached upon many paddy fields and threatened the balance of the eco-environment. Therefore, local governments should formulate extensive and strict rules to restrict the total amount of build-up area and delimited the boundary of urban development in not only large cities but also medium and small cities.

Because of the continuously widening gap between land urbanization and population urbanization, the Ministry of Land and Resources of China (MLR) declared that the amount of urban land per capita would be restricted to $80-120 \mathrm{~m}^{2} /$ person. However, the urbanization curve representing different types of urban expansion in the Hang-Jia-Hu Plain has revealed that autonomous expansion cities has already entered the terminal stage, whereas passive extensive cities are still in an acceleration stage (Figure 11). In the autonomous expansion cities, the growth of the population and urban area will be maintained at a steady state. The paddy field will be encroached upon by the increasing urban core as well as transition zones. In the passive extensive cities, economic development will continue to produce drastic land urbanization over the next decade despite the amount of urban land per capita having already reached $300.8 \mathrm{~m}^{2} /$ person, which far exceeds the suggested range as of 2010 . Therefore, the continuous transformation of paddy fields associated with built-up land expansion will be inevitable, especially in the urban fringe. Local governments should pay more attention to the urban core of autonomous expansion cities and the urban fringe of passive extensive cities. In addition, they could develop and implement rational land-use plans and compact development models to protect the paddy soils with high production. Recently, central and local government implemented the "occupied paddy, supplemented paddy" policy to protect paddy fields: if a paddy field were encroached upon, the equivalent amount of paddy was supplemented. However, the quantity of supplemental paddy field was equal to the lost area, and the quality was poorer. Therefore, adhering to the most stringent regulations of "basic farmland protection areas regulation", permanent paddy reserves that prohibit development for urban use should be defined to protect high-quality paddy fields in the Hang-Jia-Hu Plain. In addition, passive extensive cities should receive increased attention from central and local governments, which should implement strict rules to restrict the conversion of paddy fields to developed land.

Given the ecological consequences associated with paddy field loss, specific management systems targeting ecosystem conservation should be established in China. At the strategic level, a proactive ecological framework for land-use planning and urban development should encourage paddy field 
protection at the initial stage before negative impacts occur. In addition, rules and regulations should be defined and enforced, and the spatial scale of paddy soil loss should be monitored and managed.
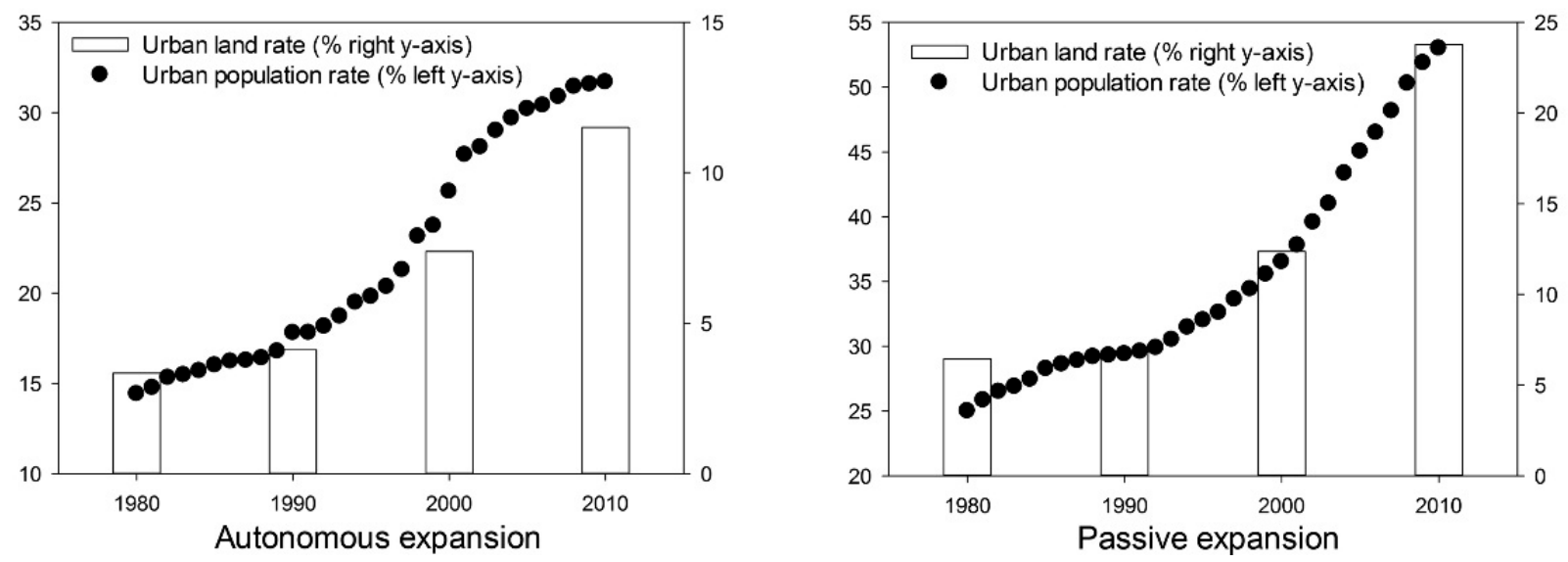

Figure 11. Trends of the urban population rate and urban land rate during 1980-2010. Note: Urban land rate is urban area to administrative area; Urban population rate is urban population to total population.

\section{Conclusions}

This paper reports a practical methodology of characterizing the spatiotemporal dynamic pattern of urban expansion and exploring the changing pattern of paddy fields in response to rapid urbanization in the Hang-Jia-Hu Plain, which is undergoing rapid changes in land use as a result of drastic paddy field loss. The integration of GIS spatial analysis, gradient paradigms and landscape metrics can be used to rapidly monitor changes caused by urbanization and to estimate their impacts on paddy fields. The results presented here reveal that accelerated social-economic development is the crucial factor in urban expansion. Of the total area of paddy fields, paddy fields of level I account for $96 \%$. Despite strict land-planning and farmland protection policies, $88 \%$ of new urban land in the Hang-Jia-Hu Plain has been converted from paddy fields.

With the progression of urbanization, autonomous expansion cities added urban cores, transitional zones and urban fringes with increasing regularity between 1980 and 2010. Relative to autonomous expansion cities, passive expansion cities have irregular expansion patterns because of the large-scale economic development areas constructed in the urban fringe in the early 1990s, which encroached on a number of paddy fields in the outer areas. In addition, urban patches became more complex and irregularly shaped in passive expansion cities. The urbanization curve implies that future urbanization will target passive expansion cities and that paddy fields will continue to face the risk of reduction. These results indicate that scientific land-use planning and efficient paddy field protection measures, such as restrictions to the boundary of urban development, compact development, delimited permanent paddy reserves and ecological oriented management systems, must be enacted.

This study focused on a typical study area in the Yangtze River Delta region with a long history of paddy cultivation experiencing rapid urbanization, where the contradiction of land use between urban land and paddy fields has been increasingly intensified by accelerated economic growth. The results distinguished among the urbanization patterns and spatiotemporal dynamic patterns of paddy fields in 
response to rapid urbanization during various stages of urbanization periods and highlighted their implications for sustainable development in the Hang-Jia-Hu Plain. The results are expected to provide a scientific basis for decision-making processes to achieve consensus among the different regional and local stakeholders. More generally, this paper has demonstrated the comprehensive application of GIS spatial analyses, gradient paradigms and landscape metrics. This comprehensive approach is a rational and efficient tool for studying paddy field dynamic patterns under human influences. Further studies should focus on the ecological consequences of urbanization on paddy fields, the impacts of landscape pattern changes on ecosystem services, and the relationships among socioeconomic development, paddy landscape pattern changes and ecosystem services valuation. With additional studies, the impact of urbanization on paddy fields will be further clarified, and decision makers will benefit by engaging in planning activities for regional sustainable development.

\section{Acknowledgments}

This research was funded by the National Science-technology Support Projects (No. 2015BAC02B06), Chinese Ministry of Environmental Protection (No. STSN-05-11) and Zhejiang Province Key Science and Technology Innovation Team (No. 2012BAH29B04). The authors thank Editor Crystal Cheng, Academic Editor Marc A. Rosen, and two anonymous reviewers for their constructive comments, suggestions and help in enhancing the manuscript.

\section{Author Contributions}

Jie Song, Ke Wang, Jinsong Deng and Zhangquan Shen had the original idea for the study and all coauthors conceived and designed the methodology. Jie Song and Dongyan Cai were responsible for the processing and analysis of the data. Jie Song drafted the manuscript, which was revised by Jinsong Deng and Ke Wang. All authors read and approved the final manuscript.

\section{Conflicts of Interest}

The authors declare no conflict of interest.

\section{References}

1. Cheng, J.; Masser, I. Urban growth pattern modeling: A case study of Wuhan City PR China. Landsc. Urban Plan. 2003, 62, 199-217.

2. Tian, G.; Liu, J.; Xie, Y.; Yang, Z.; Zhuang, D.; Niu, Z. Analysis of spatio-temporal dynamic pattern and driving forces of urban land in China in 1990s using TM images and GIS. Cities 2005, 22, 400-410.

3. Luo, J.; Wei, Y.H.D. Modeling spatial variations of urban growth patterns in Chinese cities: The case of Nanjing. Landsc. Urban Plan. 2009, 91, 51-64.

4. Chen, M.; Liu, W.; Tao, X. Evolution and assessment on China's urbanization1960-2010: Under-urbanization or over-urbanization? Habitat Int. 2013, 38, 25-33.

5. Grimm, N.B.; Faeth, S.H.; Golubiewski, N.E.; Redman, C.L.; Wu, J.G.; Bai, X.M.; Briggs, J.M. Global change and the ecology of cities. Science 2008, 319, 756-760. 
6. Grimm, N.B.; Grove, J.M.; Pickett, S.T.; Redman, C.L. Integrated approaches to long-term studies of urban ecological systems: Urban ecological systems present multiple challenges to ecologists-pervasive human impact and extreme heterogeneity of cities, and the need to integrate social and ecological approaches, concepts, and theory. Bioscience 2000, 50, 571-584.

7. Tan, P.Y.; Abdul Hamid, A.R.B. Urban ecological research in Singapore and its relevance to the advancement of urban ecology and sustainability. Landsc. Urban Plan. 2014, 125, 271-289.

8. Liu, J.Y.; Liu, M.L.; Tian, H.Q.; Zhuang, D.F.; Zhang, Z.X.; Zhang, W.; Tang, X.M.; Deng, X.Z. Spatial and temporal patterns of China's cropland during 1990-2000: An analysis based on Landsat TM data. Remote Sens. Environ. 2005, 98, 442-456.

9. Natuhara, Y. Ecosystem services by paddy fields as substitutes of natural wetlands in Japan. Ecol. Eng. 2013, 56, 97-106.

10. Lennartza, B.; Hornb, R.; Duttmannc, R.; Gerked, H.H.; Tippköttere, R.; Eickhorste, T.; Janssen, I.; Janssen, M.; Ruth, B.; Sander, T.; et al. Ecological safe management of terraced rice paddy landscapes. Soil. Till. Res. 2009, 102, 179-192.

11. Olarieta, J.R.; Rodríguez-Valle, F.L.; Tello, E. Preserving and destroying soils, transforming landscapes: Soils and land-use changes in the Vallès County (Catalunya, Spain) 1853-2004. Land Use Policy 2008, 25, 474-484.

12. Su, S.; Jiang, Z.; Zhang, Q.; Zhang, Y. Transformation of agricultural landscapes under rapid urbanization: A threat to sustainability in Hang-Jia-Hu region, China. Appl. Geogr. 2011, 31, 439-449.

13. Xiao, R.; Su, S.; Zhang, Z.; Jiang, D.; Wang, J. Local spatial modeling of paddy soil landscape patterns in response to urbanization across the urban agglomeration around Hangzhou Bay, China. Appl. Geog. 2013, 39, 158-171.

14. Sun, X.Z.; Zhou, H.L.; Xie, G.D. Ecological Services and Their Values of Chinese Agroecosystem. China Popul. Resour. Environ. 2007, 17, 55-60. (In Chinese)

15. Tan, M.; Li, X.; Xie, H.; Lu, C. Urban land expansion and arable land loss in China-A case study of Beijing-Tianjin-Hebei region. Land Use Policy 2005, 22, 187-196.

16. Cao, G.; Feng, C.; Tao, R. Local "land finance" in China's urban expansion: Challenges and solutions. China World Econ. 2008, 16, 19-30.

17. Jiang, X.C. Urbanization in China on WTO backgrounds. Urban Stud. 2003, 10, $23-34$.

18. Imhoff, M.L.; Lawrence, W.T.; Elvidge, C.D.; Paul, T.; Levine, E.; Prevalsky, M.; Brown, V. Using nighttime DMSP/OLS images of city lights to estimate the impact of urban land use on soil resources in the U.S. Remote Sens. Environ. 1997, 59, 105-117.

19. Long, H.; Liu, Y.; Wu, X.; Dong, G. Spatio-temporal dynamic patterns of farmland and rural settlements in $\mathrm{Su}-\mathrm{Xi}$-Chang region: Implications for building a new countryside in coastal China. Land Use Policy 2009, 26, 322-333.

20. Hu, X.H.; David, D.K. The emergence of affluent in Beijing: Residential social stratification in China's capital city. Urban Geogr. 2001, 22, 54-77.

21. Ding, C. Policy and praxis of land acquisition in china. Land Use Policy 2007, 24, 1-13.

22. Liu, S.; Zhang, P.; Lo, K. Urbanization in remote areas: A case study of the Heilongjiang reclamation area, northeast China. Habitat Int. 2014, 42, 103-110. 
23. Deng, J.S.; Wang, K.; Hong, Y.; Qi, J.G. Spatio-temporal dynamics and evolution of land use change and landscape pattern in response to rapid urbanization. Landsc. Urban Plan. 2009, 92, 187-198.

24. Su, S.; Ma, X.; Xiao, R. Agricultural landscape pattern changes in response to urbanization at ecoregional scale. Ecol. Indic. 2014, 40, 10-18.

25. Luck, M.; Wu, J. A gradient analysis of urban landscape pattern: A case study from the Phoenix metropolitan region, Arizona, USA. Landsc. Ecol. 2002, 17, 327-339.

26. McDonnell, M.J.; Hahs, A.K. The use of gradient analysis studies in advancing our understanding of the ecology of urbanizing landscapes: Current status and future directions. Landsc. Ecol. 2008, $23,1143-1155$.

27. Houghton, R.A.; Hackler, J.L. Sources and sinks of carbon from land-use change in China. Glob. Biogeochem. Cycl. 2003, doi:10.1029/2002GB001970.

28. Seto, K.C.; Fragkias, M. Quantifying spatiotemporal patterns of urban land-use change in four cities of China with time series landscape metrics. Landsc. Ecol. 2005, 20, 871-888.

29. Shen, W.J.; Wu, J.G.; Grimm, N.B.; Hope, D. Effects of urbanization-induced environmental changes on ecosystem functioning in the Phoenix metropolitan region, USA. Ecosystems 2008, 11, 138-155.

30. Tate, C.M.; Cuffney, T.F.; Mcmahon, G.; Giddings, E.M.P.; Coles, J.F.; Zappia, H. Use of an urban intensity index to assess urban effects on streams in three contrasting environmental settings. Am. Fish. Soc. Symp. 2005, 47, 291-315.

31. Su, S.; Xiao, R.; Zhang, Y. Multi-scale analysis of spatially varying relationships between agricultural landscape patterns and urbanization using geographically weighted regression. Appl. Geogr. 2012, 32, 360-375.

32. Li, J.D.; Deng, J.S.; Wang, K.; Li, J.; Huang, T.; Lin, Y.; Yu, H.Y. Spatiotemporal Patterns of Urbanization in a Developed Region. Sustainability 2014, 6, 4042-4058.

33. Zhou, X.L.; Wang, Y.C. Spatial-temporal dynamics of urban green space in response to rapid urbanization and greening policies. Landsc. Urban Plan. 2011, 100, 268-277.

34. Zhang, Y.H.; Ma, Q. Investigation and Evaluation of Chinese Cultivated Land Quality (Zhejiang Section); China Land Press: Beijing, China, 2010; pp. 116-126. (In Chinese)

35. Pan, X.Z.; Zhao, Q.G. Measurement of urbanization process and the paddy soil loss in Yixing city, China between 1949 and 2000. Catena 2007, 69, 65-73.

36. Su, S.; Zhang, Q.; Zhang, Z.; Zhi, J.; Wu, J. Rural settlement expansion and paddy soil loss across an ex-urbanizing watershed in eastern coastal china during market transition. Reg. Environ. Chang. 2011, 11, 651-662.

37. Liu, Y.L.; Luo, T.; Liu, Z.Q.; Kong, X.S.; Li, J.W.; Tan, R.H. A comparative analysis of urban and rural construction land use change and driving forces: Implications for urban-rural coordination development in Wuhan, Central China. Habitat Int. 2015, 47, 113-125.

38. Yeh, A.; Wu, F. Internal structure of Chinese cities in the midst of economic reform. Urban Geogr. 1995, 16, 521-554.

39. Hu, X.; Wang, W.; Sheng, H. Urban traffic flow prediction with variable cell transmission model. J. Transp. Syst. Eng. Inf. Technol. 2010, 10, 73-78. 
40. Tian, G.J.; Wu, J.G. Comparing urbanization patterns in Guangzhou of China and Phoenix of the USA: The influences of roads and rivers. Ecol. Indic. 2015, 51, 23-30.

41. Li, X.W.; Fang, J.Y.; Piao, S.L. The comparison of spatial characteristics in urban landuse growth among the central and sub-cities in Shanghai Region. Geogr. Res. 2003, 22, 769-779.

42. Tian, G.J.; Jiang, J.; Yang, Z.F.; Zhang, Y.Q. The urban growth, size distribution and spatio-temporal dynamic pattern of the Yangtze River Delta megalopolitan region, China. Ecol. Model. 2011, 222, 865-878.

43. Shoyama, K.; Braimoh, A.K. Analyzing about sixty years of land-cover change and associated landscape fragmentation in Shiretoko Peninsula, Northern Japan. Landsc. Urban Plan. 2011, 101, 22-29.

44. Pijanowski, B.C.; Ray, D.K. Rates and patterns of land use change in the Upper Great Lakes States, USA: A framework for spatial temporal analysis. Landsc. Urban Plan. 2011, 102, 102-116.

45. IRRI. China. Available online: http://irri.org/our-work/locations/china (accessed on 20 August 2015).

46. Zhang, X.; Chen, J.; Tan, M.; Sun, Y. Assessing the impact of urban sprawl on soil resources of Nanjing city using satellite images and digital soil databases. Catena 2007, 69, 16-30.

47. Ewing, R.H. Characteristics, causes, and effects of sprawl: A literature review. Environ. Urban Stud. 1994, 21, 519-535.

48. Thompson, A.W.; Prokopy, L.S. Tracking urban sprawl: Using spatial data to inform farmland preservation policy. Land Use Policy 2009, 26, 194-202.

49. Markus, A.; Djadja, S. Assessing soil properties and tidal behaviors as a strategy to avoid environmental degradation in developing new paddy fields in tidal areas. Agric. Ecosyst. Environ. 2013, 181, 90-100.

(C) 2015 by the authors; licensee MDPI, Basel, Switzerland. This article is an open access article distributed under the terms and conditions of the Creative Commons Attribution license (http://creativecommons.org/licenses/by/4.0/). 